\title{
An online solution focused brief therapy for adolescent anxiety during the novel coronavirus disease (COVID-19) pandemic: a structured summary of a study protocol for a randomised controlled trial
}

\author{
Shitao Chen (1D
}

\begin{abstract}
Objectives: This study aims to assess the effectiveness of delivering Solution Focused Brief Therapy (SFBT) through telecommunication with a group of adolescents who present anxiety symptoms during the COVID-19 outbreak. We hypothesize that participants who are randomly assigned to receive 2-4 sessions of Solution Focused Brief Therapy would have better clinical outcomes than participants who are in the waitlist group. We additionally hypothesized that using SFBT can also change participants' depression levels and their coping strategies in dealing with distress during the COVID-19 pandemic.

Trial design: This study employs a randomized delayed crossover open label controlled trial in adolescents who are presenting anxiety symptoms during the COVID-19 outbreak. Participants who meet the enrollment criteria stated below will be invited to participate in this study through telecommunication. Those accepting will be randomly allocated to the intervention group or waitlist group.

Participants: The inclusion criteria for participants are:

1. Adolescents between 11 and 18 years old who are currently in grade 7-12

2. Manifesting anxiety symptoms during the COVID-19 outbreak and Generalized Anxiety Disorder (GAD) $7 \geq 10$

3. Having a legal guardian who has signed the informed consent and an adolescent willing to participate in this study

4. Have a stable internet condition and a quiet space for receiving internet-based counseling
\end{abstract}

The exclusion criteria are:

1. Reporting suicidal ideation or plan during the past 2 weeks

2. Receiving counseling service elsewhere

(Continued on next page)

Correspondence: chenshitao@bnu.edu.cn

Beijing Normal University, Faculty of Psychology, Beijing, China

C C The Author(s). 2020 Open Access This article is licensed under a Creative Commons Attribution 4.0 International License, which permits use, sharing, adaptation, distribution and reproduction in any medium or format, as long as you give appropriate credit to the original author(s) and the source, provide a link to the Creative Commons licence, and indicate if changes were made. The images or other third party material in this article are included in the article's Creative Commons licence, unless indicated otherwise in a credit line to the material. If material is not included in the article's Creative Commons licence and your intended use is not permitted by statutory regulation or exceeds the permitted use, you will need to obtain permission directly from the copyright holder. To view a copy of this licence, visit http://creativecommons.org/licenses/by/4.0/. The Creative Commons Public Domain Dedication waiver (http://creativecommons.org/publicdomain/zero/1.0/) applies to the data made available in this article, unless otherwise stated in a credit line to the data. 
(Continued from previous page)

3. Taking psychiatric medication

4. Having another severe mental health diagnosis (e.g., bipolar disorder, psychosis)

5. Unwilling to have legal guardian sign the informed consent or participate in this study

All data were collected through a Chinese online survey tool called "Wen Juan Xing" (https://www.wjx.cn/) from the Faculty of Psychology at Beijing Normal University.

Intervention and comparator: The intervention group will receive Solution Focused Brief Therapy 2-4 times within a 2 week period through telecommunication (e.g., using a platform such as Zoom). The comparators will be assigned to the waitlist group. They will also receive $2-4$ sessions of counseling service after the 1 month follow-up data is collected.

Main outcomes: The primary outcome measures of the study are intended to assess the difference in adolescents' anxiety levels when comparing the SFBT group and the waitlist group. Level of anxiety will be measured by two measurements: GAD-7 and STAI-Y (C). Follow up 2 weeks and 1 month.

Baseline scores (GAD-7, STAI-Y(C), PHQ-9, CSS) will be collected from all participants and their legal guardian (Spence Children's Anxiety Scale-Parent report, Patient Health Questionnaire - 9) before beginning treatment. After 2 weeks' treatment, participants from both the intervention group and waitlist group will complete the assessments (GAD-7, STAI-Y(C), PHQ-9, CSS, CSQ-8), and their legal guardian will also complete several assessments (SCAS-Parent report, $\mathrm{PHQ}-9)$. After 1 month of treatment, data will be collected again.

Note: GAD-7 (Generalized Anxiety Disorder-7); STAI-Y(C) (State-Trait Anxiety Inventory); PHQ-9 (Patient Health Questionnaire-9); CSS (Coping Style Scale for Secondary School Students); CSQ-8 (Client Satisfaction Questionnaire8), SCAS (Spence Children's Anxiety Scale).

Randomization: The Random Number Generator, an internet-based randomization tool, is used to assign participants to the intervention group and waitlist group. The allocation ratio is 1:1.

Blinding (masking): Participants will be informed about the group assignment due to the nature of the study design. The research assistant who will have access to the outcome data is blinded to group assignment.

Numbers to be randomized (sample size): The study plans to enroll a total of 76 participants. Thirty-eight participants are to be randomized to each group.

Trial status: The Protocol version number is 02, with ethical approval number 202003130012 . The recruitment is ongoing. It started on March 20th, and we estimate it will finish by the 30 June 2020.

Trial registration: The trial was registered with the Chinese Clinical Trial Registry on March 20th, 2020. Registration number is ChiCTR2000030989.

Full protocol: The full protocol is attached as an additional file, accessible from the Trials website (Additional file 1). In the interest of expediting dissemination of this material, the familiar formatting has been eliminated; this letter serves as a summary of the key elements of the full protocol.

Keywords: COVID-19, Randomized controlled trial, Protocol, Solution focused brief therapy, Adolescents, Anxiety

\section{Supplementary information}

Supplementary information accompanies this paper at https://doi.org/10. 1186/s13063-020-04355-6.

Additional file 1: Full-study protocol in Chinese.

\footnotetext{
Acknowledgements

The author would like to thank the following colleagues who provided counseling services to our adolescent clients: Wenxiu Bi, Peiyu Chen, Jing Wang, Quan Yuan, Xiaoying Feng; the research assistants who contacted the clients and made this project run smoothly: Lanxin Guo, Ying Zhong, Jiafan He; and the assessment team who assisted with the structured anxiety screening: Zihui Liu, Yonglan Yu, Yuxi Chen, Fei Wu, and Jing Wu. The author also wants to thank Beijing Normal University, Faculty of Psychology, Mental Health Service, which provided the platform to conduct this project, and Runsen Chen, an outside
}

consultant who provides feedback to the design of the study and the implementation of the research.

\section{Author's contributions}

SC designed the entire study, provided training and supervision for counselors, supervised intervention delivery of this study, and wrote the study protocol. The author(s) read and approved the final manuscript.

\footnotetext{
Author's information

SC received her doctoral degree in School Psychology at Indiana University in 2017. Currently, she is one of the staff psychologists and the leader of the Children and Adolescents' Treatment Team at Beijing Normal University, Faculty of Psychology, Mental Health Service. She is one of the core members of the team that initiated China's first University-Based mental health program to build a working team and provide hotline and online counselling services to the Chinese public during the COVID-19 outbreak.
} 


\section{Funding}

Beijing Normal University Education Foundation will provide funding for this study.

Availability of data and materials

SC and JH will have access to the final trial dataset. The dataset will be available from the author upon reasonable request. The contact email address is chenshitao@bnu.edu.cn

\section{Ethics approval and consent to participate}

The Ethics Committee of Beijing Normal University Faculty of Psychology approved the study on March 13th, 2020. The Approval number of the study is 202003130012 . I certify that this trial has received ethical approval from the appropriate ethical committee as described above. Informed consent for participating in the study and for receiving counseling services will both be sent out to all participants and their legal guardians to sign and must be first completed in order for them to be enrolled in this study.

\section{Consent for publication}

Not applicable.

\section{Competing interests}

The author declares that she has no competing interests.

Received: 23 April 2020 Accepted: 27 April 2020

Published online: 13 May 2020

\section{Publisher's Note}

Springer Nature remains neutral with regard to jurisdictional claims in published maps and institutional affiliations.

- fast, convenient online submission

- thorough peer review by experienced researchers in your field

- rapid publication on acceptance

- support for research data, including large and complex data types

- gold Open Access which fosters wider collaboration and increased citations

- maximum visibility for your research: over $100 \mathrm{M}$ website views per year

At BMC, research is always in progress. 